\title{
An ecumenical response to color contrast cases
}

\author{
Pendaran Roberts ${ }^{1}$
}

Received: 1 August 2015 / Accepted: 5 January 2016 / Published online: 2 February 2016

(C) The Author(s) 2016. This article is published with open access at Springerlink.com

\begin{abstract}
Intrapersonal variation due to color contrast effects has been used to argue against the following intuitive propositions about the colors: No object can be more than one determinable or determinate color of the same grade all over at the same time (Incompatibility); external objects are actually colored (Realism); and the colors of objects are mind-independent (Objectivism). In this article, I provide a defense of Incompatibility, Realism, and Objectivism from intrapersonal variation arguments that rely on color contrast effects. I provide a novel, ecumenical response to such arguments according to which typical variants are right, and which respects Incompatibility, Realism, and Objectivism, using the thesis that the colors of objects depend on the colors of objects in their surrounds.
\end{abstract}

Keywords Color contrast · Incompatibility · Objectivism · Realism

\section{Introduction}

In the Essay, Locke famously said, "Let the eyes not see light or colours [...] and all colours [...] vanish and cease, and are reduced to their causes, i.e. size, shape, and motion of parts" (2004, II-viii-17). Color has struggled to gain the same status as the quintessential objective property shape ever since. Despite this, the following propositions, which mutatis mutandis seem true for shapes, seem true for colors (Westphal 1987, 2005; Byrne and Hilbert 2003a; Allen 2009b):

Pendaran Roberts

pendaran@mac.com

1 University of Warwick, Coventry, UK 
Incompatibility: No object can be more than one determinable or determinate color of the same grade all over at once. (The term 'color' in this proposition and elsewhere refers to those properties in the familiar color solid. Also, to be clear, 'object' here and throughout the paper should be interpreted broadly.)

Realism: External objects are actually colored. (When one sees a tomato one sees a quality 'redness' that belongs to the surface of the tomato. Realism implies that external objects actually have such qualities. If we have veridical experiences as of the colors of external objects, Realism is true, but the converse is false. External objects could be colored even though we never see their colors veridically. For instance, logically, everyone could have color spaces that do not align with reality.)

Objectivism: The colors of objects are mind-independent. (This should be understood as saying that the colors of objects do not depend in any way on minds. So, the colors are not constituted by minds, and external objects would retain their colors even if all color seeing conscious creatures were abolished from existence.)

What I call 'the (color) variation argument' is an abductive argument abstracted from various things that philosophers have said to undermine at least one or another of Incompatibility, Realism, and Objectivism. Locke notably used such arguments to arrive at the famous conclusion previously quoted. Color variation occurs whenever two (or more) perceptual experiences represent one object as having two (or more) seemingly incompatible colors. The argument presupposes the empirical premise that there is at least interspecies, interpersonal, or intrapersonal color variation. Interspecies variation occurs whenever two (or more) species' experiences represent that one object is two (or more) conflicting colors in the same circumstances. Interpersonal color variation occurs whenever two (or more) subjects' experiences represent that one object is two (or more) conflicting colors in the same circumstances. Intrapersonal color variation occurs whenever a single subject's experiences represent that one object is two (or more) conflicting colors in two (or more) different circumstances. The variation argument runs as follows:

$\mathrm{P} 1$. There is no reason why one variant is veridical rather than another in $X$ type color variation cases (where $X$ is filled in with a type of color variation, e.g. intrapersonal).

$\mathrm{P} 2$. The best explanation of P1 is one of the following: Incompatibility is false; or Realism is false; or both Incompatibility and Objectivism are false.

3. Therefore, one of the following is plausibly false: Incompatibility; or Realism; or both Incompatibility and Objectivism.

Cohen $(2004 ; 2009)$ uses a form of this argument to support his relational view that the colors are constituted by relations to subjects. He thinks that the best explanation of P1 is that both Incompatibility and Objectivism are false. Selectionists use a form of this argument to support their view that different visual systems pick out disparate properties as being the colors (Kalderon 2007; Mizrahi 2007; Allen 2009b). Selectionists can be interpreted as believing that the best explanation of P1 is that Incompatibility 
is false. Color relativists use a form of this argument to support their view that objects only have colors relative to perceivers (Brogaard 2010; Egan 2010). Cohen's view can be understood as holding that objects have relational properties relative to worlds. In contrast, relativism holds that objects are colored relative to centered worlds. ${ }^{1}$ Color relativists believe that the best explanation of P1 is that both Incompatibility and Objectivism are false. Finally, eliminativists use a form of this argument to support their view that external objects are not actually colored (Boghossian and Velleman 1989; Hardin 1988, 2004; Maund 1995; Chalmers 2006). Eliminativists think that the best explanation of $\mathrm{P} 1$ is that Realism is false.

There are two versions of the variation argument, depending on whether one interprets P1 metaphysically or epistemically. The metaphysical and epistemic interpretations of $\mathrm{P} 1$ respectively are as follows:

M1. There is nothing to make one variant veridical rather than another in $X$ type color variation cases.

E1. There is no reason to believe that one variant is veridical rather than another in $X$ type color variation cases.

I will focus on a particularly compelling instance of the intrapersonal variation argument, which I call 'the color contrast argument.' It is important that one allow this variation argument to be considered independent of the rest, because proponents of Incompatibility, Realism, and Objectivism give different responses to different instances of the argument. Allen responds to the interpersonal variation argument by denying that interpersonal variation is all that pervasive (or widespread) in the first place (2010) and to the interspecies variation argument by accepting a kind of limited selectionism (2009b). ${ }^{2}$ I continue this method of responding to the different instances differently. First, I set up the color contrast argument (Sect. 2). Next, I question the popular 'dogmatic response' to the metaphysical version of it (Sect. 3). I then provide a novel, ecumenical response to the metaphysical version of the color contrast argument under which typical variants are right that respects Incompatibility, Realism, and Objectivism using the idea that the colors of objects depend on the colors of objects in their surrounds (Sect. 4). At the end of this section, I show that the response also handles the epistemic version of the color contrast argument. Finally, I respond to a series of objections against the provided, ecumenical response (Sect. 5).

\section{The color contrast argument}

In this section, I explain the color contrast argument in detail. Color contrast effects occur whenever the color of one object that reflects a particular proportion of incident

\footnotetext{
1 To say that objects are colored relative to worlds is to say that whether something $x$ is red depends on which world one looks into. For Cohen, objects can be multiply-colored, even so these colors hold at worlds. There is a fact about the colors objects have at worlds. Centered worlds are ones in which agents and times are designated. So, to say that objects are colored relative to centered worlds is to say that whether something $x$ is red depends on not only the world one looks in but also on which person in it one looks at and at which particular time one does the looking. There is no fact about what colors things have at worlds. To read more about centered worlds see Lewis (1979), Brogaard (2010), and Liao (2012).

2 Byrne and Hilbert (2003a, b, 2004, 2007) reply to a general form of the interpersonal argument. Their reply is different again from Allen's. So, there are many possible replies.
} 
light (at each visible wavelength) appears to change color depending on the proportion or proportions of incident light reflected (at each visible wavelength) by one or more objects in its surround. Color contrast is different from 'color composition' whereby the colors of an object's parts (e.g. the individual blood cells) affect the color the whole object (the blood) appears. Color composition does not count as color contrast (at least not given my definitions of these terms), because the parts of a whole are not surrounding the whole but parts of it. (Likewise, color contrast is different from 'reverse color composition' whereby the color of a whole object affects the colors the parts of the object appear.)

Although color contrast is not the same thing as color composition, color composition is a type of color variation. Thus, a variation argument could be constructed using the concept. Hilbert $(1987, \S 2)$ would say that the intuitive reply to such a variation argument is to reject the relevant instance of P2. Specifically, he would say that the best explanation of the instance of P1 that fills in $X$ with 'color composition' is not that Incompatibility, or Realism, or Incompatibility and Objectivism is false but that the color of a whole changes depending on the colors of its parts similar to how the shape of an object changes depending on the shapes of its parts. I agree with this, and as shall be seen, pursue a similar style of response to the color contrast argument. This said, color composition is not color contrast.

As previously mentioned, color contrast effects occur whenever one object that reflects a particular proportion of incident light appears to change color depending on the particular proportion or proportions of incident light reflected by another object or objects in its surround. There are (standardly) considered to be simultaneous color contrast effects, which involve an object or objects in the surrounding space, and successive contrast effects, which involve an object or objects in the surrounding time (Hardin 1988). Let us look at some examples, but it is important to note that, given the non-dynamic medium, the examples cannot really involve one object changing its surround in space or through time. (Please see the online version for colored versions of Figs. 2, 3.)

The central squares in the simultaneous color contrast example in Fig. 1 reflect the same proportion of incident light. However, typical observers in typical conditions
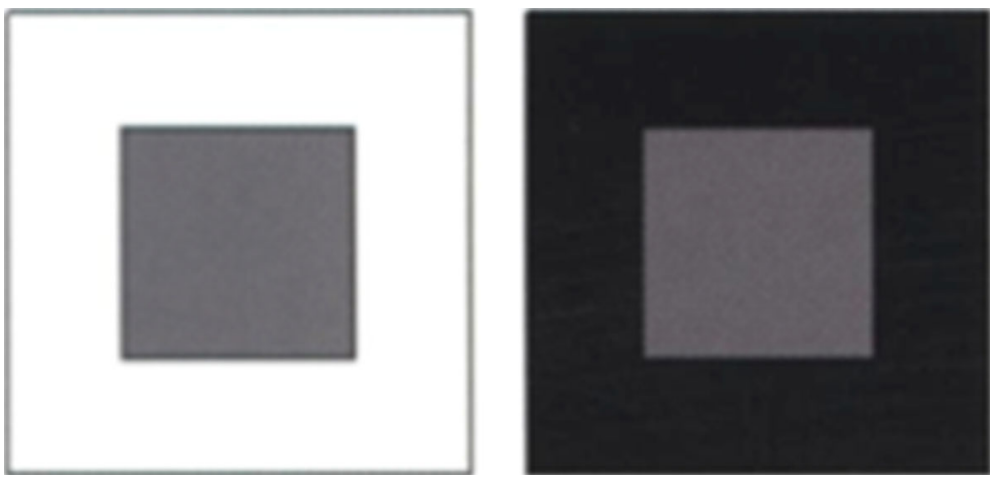

Fig. 1 Simultaneous contrast example one (Cohen 2004, 2009) 
report that the central squares look different colors depending on the colors of the objects in their surrounds. In this example, typical observers in typical conditions report that the right central square looks lighter than the left central square.

The thin vertical strips in the simultaneous color contrast example in Fig. 2 reflect the same proportion of incident light. Nevertheless, typical observers in typical conditions report that the strips look different colors depending on the colors of the objects in their surrounds. In this case, typical observers in typical conditions usually report that the left strip looks lighter than the right one.

The bottom disks in the successive color contrast example in Fig. 3 reflect the same proportion of incident light. Nevertheless, typical observers in typical conditions who stare at the center dot in either of the colored disks in the top row and then look at the dot in the center of the disk of the same column in the bottom row report that the bottom disk appears to briefly change color.

Successive color contrast effects do not create an instance of the variation argument as equally compelling as simultaneous color contrast effects. Successive color contrast effects, unlike simultaneous contrast effects, seldom appear in perception to be veridical. The center squares and the strips in Figs. 1 and 2 respectively appear in perception to be veridical. In contrast, the successive color contrast effects created using the example of Fig. 3 do not appear in perception to be veridical. Phenomenologically, it is as if there is an afterimage of the disk stared at first overlapping (in some sense) the bottom disk being looked at second. If successive contrast effects do not appear veridical, there is no pressure to accept any instance of $\mathrm{P} 1$ of the variation argument that fills in $X$ with 'successive color contrast.'

Thus, the color contrast argument shall be stated only in terms of simultaneous color contrast. Specifically, the abductive argument will be stated using simultaneous color contrast effects that occur whenever one object that reflects a particular proportion of incident light appears to change color to typical (human) observers in typical conditions (or something similar) depending on the particular proportions of incident

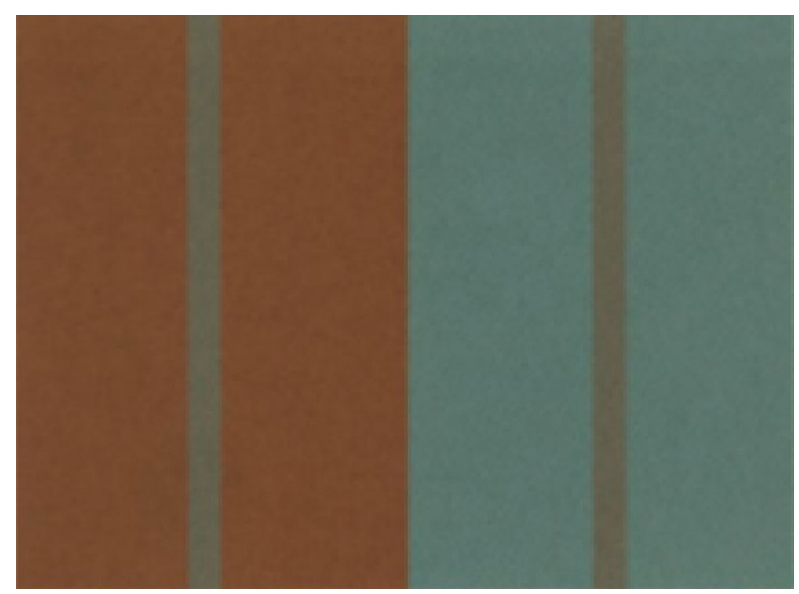

Fig. 2 Simultaneous contrast example two (Cohen 2004, 2009) 

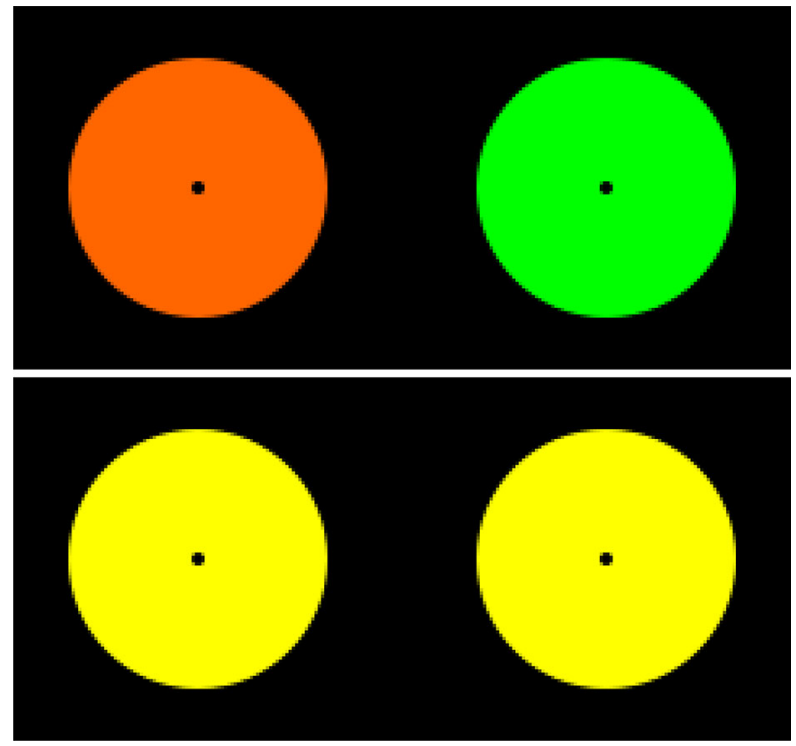

Fig. 3 Successive color contrast example

light reflected by objects in its surround. ${ }^{3}$ This makes for the strongest version of the argument, which runs as follows:

$\mathrm{P} 1^{\text {con }}$. There is no reason why one variant is veridical rather than another in intrapersonal color variation cases involving simultaneous color contrast effects and typical observers in typical conditions (or something similar).

$\mathrm{P} 2^{\text {con }}$. The best explanation of $\mathrm{P}^{\text {con }}$ is one of the following: Incompatibility is false; or Realism is false; or both Incompatibility and Objectivism are false.

3. Therefore, one of the following is plausibly false: Incompatibility; or Realism; or both Incompatibility and Objectivism.

Just as is the case with the general variation argument form, there are two versions of the color contrast argument depending on whether one interprets $\mathrm{P} 1{ }^{\mathrm{con}}$ metaphysically or epistemically. The interpretations of P1 respectively are as follows:

$\mathrm{M}^{\mathrm{con}}$. There is nothing to make one variant veridical rather than another in intrapersonal color variation cases involving simultaneous color contrast effects and typical observers in typical conditions (or something similar).

$\mathrm{E} 1^{\mathrm{con}}$. There is no reason to believe that one variant is veridical rather than another in intrapersonal color variation cases involving simultaneous color contrast effects and typical observers in typical conditions (or something similar).

One gets the metaphysical version of the color contrast argument by replacing $\mathrm{P}^{\text {con }}$ with $\mathrm{M} 1^{\text {con }}$ and making the appropriate changes to $\mathrm{P} 2^{\text {con }}$ to create $\mathrm{M} 2^{\mathrm{con}}$ :

\footnotetext{
3 I have parenthetically added 'or something similar', because the exact conditions under which we usually perceive veridically are unobvious. This is not a topic I can further engage with in this article.
} 
The best explanation of $\mathrm{M}^{\mathrm{con}}$ is one of the following: Incompatibility is false; or Realism is false; or both Incompatibility and Objectivism are false.

One gets the epistemic version of the color contrast argument by replacing $\mathrm{P} 1^{\text {con }}$ with $\mathrm{E} 1^{\text {con }}$ and making the appropriate changes, now obvious, to $\mathrm{P} 2^{\mathrm{con}}$ to create $\mathrm{E} 2^{\mathrm{con}}$. I shall mainly focus on the metaphysical version of the color contrast argument, but using what I say in response to this version, I shall later engage with and dismiss the epistemic version.

\section{The dogmatic reply}

An immediate retort to the metaphysical color contrast argument is to say that there is something to make one variant veridical rather than another in simultaneous color contrast cases involving typical observers in typical conditions, namely the colors. Hence, why should one believe M1 ${ }^{\text {con }}$ is true? Cohen (2009, p. 22) when arguing for his relationalist view on color by making the case for a general variation argument specifically says the following:

'[...] it is difficult to imagine a well motivated, principled, and non-questionbegging answer. That is to say, it is hard to imagine what, other than stipulation, could make it the case that one of the backgrounds [...] is such that when the stimulus is viewed against that one, it is visually represented as bearing the color that it has.'

Now, although other arguments in favor of M1 ${ }^{\text {con }}$ could perhaps be developed, this argument, which I call 'the hard-to-imagine argument,' is very popular (Cohen 2004, 2006a; Kalderon 2007; Mizrahi 2007). Given the cases of color contrast dealt with in this article, the hard-to-imagine argument is best put like this: it is hard to imagine what could make one experience as of the simultaneous color contrast examples had by a typical observer in typical conditions veridical rather than another. Thus, it must be the case that there is nothing to make one experience as of the simultaneous color contrast examples (had by a typical observer in typical conditions) veridical rather than another. Therefore, $\mathrm{M}^{\text {con }}$ must be true.

The dogmatic reply was originally proposed by Tye (2000) and Byrne and Hilbert (2003b; 2004; 2007) to defend their reflectance dispositionalist view (that colors are dispositions to reflect certain proportions of incident light at each wavelength of the visible spectrum) from the variation argument. For the purposes of this article, the dogmatic reply will be presented and discussed more generally as a defense of Incompatibility, Realism and Objectivism. Thus understood, the dogmatic reply to the metaphysical color contrast argument is to reject $\mathrm{M}^{\text {con }}$ by rejecting the hard-toimagine argument. Specifically, the response is to reject $\mathrm{M} 1^{\text {con }}$ by saying that it is not difficult to imagine what could make at most one experience as of the simultaneous color contrast examples veridical rather than another. What could make at most one experience as of one of the central squares veridical, for instance, is if at most one experience coincided with the actual color of the squares. A likely retort is to say that this reply is question begging, but Byrne (2006) would say that this confuses the dialectic: the reply is trying to defend the intuitive propositions Incompatibility, 
Realism, and Objectivism, not argue that they are true. Another likely retort is to say, for instance, that being red is like being funny, and so we should hold that whether something is red is mind-dependent (Cohen 2006a, note 7); but Byrne would say that whether this analogy holds is the very issue under discussion (2006). ${ }^{4}$

Although the dogmatic reply is not clearly harmed by the objections just considered, there is a better reason to worry about whether the reply can ultimately succeed that stems from the fact that there seems to be strong empirical support for the claim, call it 'Pervasiveness,' that color contrast effects are pervasive in our environment (Hardin 1988; Thompson 1995; Allen 2011). I must define two more terms.

Veridicality: Typical observers' color experiences veridically represent the colors in typical conditions (or something similar).

Dependence: The colors of objects depend on (the colors of objects in) the surround (within which they are placed).

Having defined these terms, the worry with the dogmatic response is that any reply to the color contrast argument that rejects $\mathrm{M} 1^{\text {con }}$ implies that Dependence is false, but given that Pervasiveness seems to be an empirical fact, if Dependence is false, it seems one must reject Veridicality or Incompatibility. So, more directly, the concern with the dogmatic reply is that it seems to commit one to the falsity of Veridicality or Incompatibility.

Byrne and Hilbert (2003a, b, 2004) say that one ought to distinguish between color and the conditions necessary to perceive color. I agree. So, I admit that one can accept that some experiences as of simultaneous color contrast are veridical without accepting Dependence or rejecting Incompatibility. For instance, I acknowledge that experiences as of related colors (colors that can only be seen as a consequence of contrast, Hardin 1988) like white, gray, black, and brown can in principle be seen veridically even if Dependence is false and Incompatibility true. One can say that contrast effects are necessary to perceive related colors even though they do not depend on the surround. However, a distinction between color and the conditions necessary to perceive color is insufficient to avoid the above worry, for the empirical evidence suggests that color contrast effects are just too pervasive. Color contrast effects are not isolated to related colors. Complementary colors reciprocally evoke each other. Red makes an adjacent color appear greenish, blue gives an adjacent color an orange tinge, purple makes an adjacent color appear slightly yellow, etc. (Goethe 1810; Allen 2011).

\footnotetext{
4 Cohen (2006b) has an argument that we should treat colors like humor properties. He argues that (1) we do not make inductions about the causal effects of, for example, red things. But, he says, (2) 'if we do not make such inductions about red things, this shows that we are not committed to (indeed, we are doubtful of) the existence of any shared constitutive ground for our inductions about being red' (2006b, pp. 434-435). Cohen concludes from this that (3) colors are analogous to humor properties, not objective properties like having a temperature.

It is clear that this is a separate argument from the color variation based ones with which I am concerned, because its conclusion that the colors are like humor properties and so subjective in character does not depend on there being color variation cases. So, I will not consider this argument in depth. Regardless, I believe that it is worth quickly pointing out that the first premise is suspect at best. Here is one inductive inference about the causal effects of colored things: All the black cars I have owned get really hot in the summer; therefore, if I buy this black car the car is going to be too hot in the summer.
} 
The dogmatist should neither reject Incompatibility nor Veridicality. If one is willing to accept that Incompatibility is false, then one ought not to reject $\mathrm{M} 1^{\text {con }}$ as the dogmatists do, because Incompatibility should not be rejected without argument. So, if the dogmatist wanted to reject Incompatibility, he would need to supply an independent argument for doing so. This said, the dogmatist, of course, does not want to reject Incompatibility. He is trying to secure Incompatibility, Realism, and Objectivism from the color contrast argument. If Veridicality is false, then why should we trust our color intuitions? Trust in these intuitions must surely be based on us having reliable perceptual access to the colors. Of course, it is logically possible that the intuitions would be accurate despite being based on an unreliable sense, but it would not be good epistemic practice to trust them, at least not without countervailing evidence that the sense in question generates accurate intuitions despite being inaccurate in other ways. If we should not trust our intuitions about the colors, it is hard to see why our intuitions for Incompatibility, Realism, and Objectivism should be trusted. ${ }^{5}$ Thus, it would seem that one should not reject Veridicality who accepts the dogmatic reply, a response that is trying to secure Incompatibility, Realism, and Objectivism.

One may respond that we could trust the relevant intuitions even if Veridicality were false, because we would still typically perceive the determinable colors veridically. Dissimilar to what is the case with determinate colors, color contrast effects seldom cause an object to appear a different determinable color (although this does happen, see Fig. 2). Unfortunately, as we do not only experience, for example, that an object is red but also the particular shade of red it is, this response still implies that our color perceptions are almost always misleading (to a notable degree), and it is hard to see why we should entirely trust our intuitions about the colors if our perceptions of them are so often misleading. If they are so often misleading, it seems that at best we should be confident that our intuitions are somewhat right, but this is not sufficient for the dogmatist. The dogmatist wants to secure Incompatibility, Realism, and Objectivism, not something somewhat like them! So, not only does the dogmatic response seem to force one to reject Veridicality or Incompatibility, but also it would seem that, dialectically, the proponent of the reply ought not to reject either! Thus, in my opinion the dogmatic response is not a viable way for the proponent of Incompatibility, Realism, and Objectivism to reply to the color contrast argument.

\section{A novel, ecumenical reply}

I want to uphold Incompatibility, Realism, and Objectivism. Thus, given the last section, I do not think it is dialectically open for me to reject Veridicality. As I mentioned, Allen (2010) rejects pervasiveness for interpersonal variation. Most of the interpersonal variation, he argues, surrounds one color: unique green. Roberts and Schmidtke (2012) also question pervasiveness for interpersonal variation. They question whether

\footnotetext{
5 A referee pointed out that an even stronger conclusion may be warranted: if we should not trust our intuitions about the colors, the whole project of determining a color ontology is undermined. If we cannot trust our intuitions about the colors, how could we determine what the colors are? I am sympathetic to the referee's argument, but it is stronger than what I need in this section. So, I will not further engage with the argument in this article.
} 
the evidence supports the claim that there is pervasive perceptual variation rather than just conceptual variation. I am open to someone pursuing similar strategies with Pervasiveness. If Pervasiveness were false, the dogmatist would avoid having to reject either Veridicality or Incompatibility. However, what has not yet been noticed is that, unlike the interpersonal variation argument where the proponent of Incompatibility, Realism, and Objectivism cannot accept a dependence on subjects, the proponent can respond to the color contrast argument by simply accepting Dependence. Dependence is logically compatible with Incompatibility, Realism, and Objectivism. As this reply allows one to avoid the argument without having to even question the empirical evidence, this novel response is a very satisfying solution.

If Pervasiveness is true and one wants to uphold Incompatibility and Veridicality, then one must accept Dependence. Pervasiveness has strong empirical support (Hardin 1988; Thompson 1995; Allen 2011). So, anyone who wants to uphold Incompatibility and Veridicality has good reason to believe Dependence. Dependence is compatible with Incompatibility, Realism, and Objectivism. So, the proponent of Incompatibility, Realism, and Objectivism has good (but defeasible) reason to accept Dependence. The idea is that instead of rejecting $\mathrm{M}^{\text {con }}$ like the dogmatic response, this novel response to the color contrast argument is to accept $\mathrm{M} 1^{\text {con }}$ but reject $\mathrm{M} 2^{\text {con }}$ by accepting that the colors of objects are dependent on the colors of the surround. ${ }^{6} \mathrm{M} 1^{\text {con }}$ is true, but if Dependence is true, the best explanation of this is not that Incompatibility, or Realism, or Incompatibility and Objectivism is false but that Dependence is true. Thus, accepting Dependence allows one to hold an ecumenical view with regard to color contrast effects while preserving Incompatibility, Realism, and Objectivism.

One can differentiate between three versions of Dependence, as follows:

Contingent Dependence: The colors of objects contingently depend on the surround.

Necessary Dependence: The colors of objects necessarily depend on the surround.

Essential Dependence: The colors of objects essentially depend on the surround. (Essentiality is stronger than necessity. It is necessary to Socrates that he is in the singleton set containing Socrates, but it is not essential to him, Fine 1994.)

To determine which version of Dependence is correct would require discussion of issues that cannot be addressed here. For example, Hume's dictum (Hume 2004, I-iii-6) (that there are no necessary connections between distinct existences) is clearly relevant to whether Contingent Dependence or something stronger is true. However, I do wish to discuss whether any of the versions of Dependence imply that the colors are relational properties. Contingent Dependence does not, for relational properties are at least necessarily relational. With respect to Necessary Dependence, there is room for debate, because there is no universally accepted analysis of 'relational property' (Cohen 2004, 2009). This said, according to Roberts (2014), Necessary Dependence would not imply that the colors are relational properties: an essential dependence is required. Assuming Essential Dependence is true, Roberts (2014) would accept that

6 I provide a more thorough way of understanding 'the surround' in Sect. 5 in response to the fourth objection I consider. 
the colors are relational properties (in a liberal sense). ${ }^{7}$ Importantly though, even if the relevant relational view were true, Cohen's relational view need not be, because Dependence but not Cohen's view is compatible with Incompatibility, Realism, and Objectivism.

Dependence is not a thesis about what the colors are; it only states that the colors of objects depend on the surround. So, Dependence, taken alone, is compatible with any extant view on what the colors are that can be modified to hold that the colors are (typically) extrinsic (in a broad sense): if an extant view is flexible enough to be modified to hold that the colors are (typically) extrinsic, then it can be made compatible with Dependence. ${ }^{8}$ There is only one extant view on what the colors are that clearly cannot be modified to allow for the colors being extrinsic: reflectance dispositionalism (Byrne and Hilbert 2003a; Tye 2000). ${ }^{9}$ Although Dependence, taken alone, is compatible with any extant view on what the colors are that can be modified to hold that the colors are extrinsic, it would be inconsistent with this article's purpose to accept a view that is incompatible with the propositions I am defending from the color contrast argument by proposing Dependence: Incompatibility, Realism, and Objectivism. Which of the extant views on what the colors are can be modified to hold that the colors are extrinsic and hold these propositions? There are two clear possibilities: micro-structuralism and primitivism.

Micro-structuralism is the view that the colors are micro-structural properties of objects that are physical in a narrow sense (Kripke 1972; Jackson and Pargetter 1987). At least some such properties are compatible with Incompatibility, Realism, and Objectivism. Further, there are micro-structural properties that are narrowly physical and (typically) extrinsic, for example, the property of having such and such an electronic configuration (the distribution of electrons in an atom or molecule). Thus, micro-structuralism can be modified to accommodate Dependence and the three other propositions. Accepting Dependence and thus modifying micro-structuralism accordingly could help the view to avoid the problem of multiple causes: that there are no clear criteria by which to select, for example, blue from among the many microstructural causes of experiences as of blue things (Nassau 1983, 1997; Watkins 2002, p. 21). My argument for Dependence provides one necessary condition: the relevant property must be extrinsic in the right way (it must depend on the colors of objects in the surround against which it is placed). This condition may go a long way to helping micro-structuralism overcome the problem of multiple causes. What if there is only one micro-structural property extrinsic in the right way which is plausibly the property blue?

\footnotetext{
7 Roberts (2014) makes a distinction between strict and liberal notions of 'relational property.' The strict version requires a relation to things, where the sense of 'things' is that understood by the first-order quantifier. On the other hand, the liberal version of the notion 'relational property' interprets 'things' much more broadly. The colors of objects are not things in the strict sense but only the liberal since.

8 For example, plausibly a dispositional view could be made compatible with Dependence, because plausibly some dispositions are extrinsic (e.g. the disposition to open Shoemaker's front door) (McKitrick 2003). Standard dispositionalism that red is the disposition to appear red, though, is necessarily incompatible with Objectivism, given the strong sense of 'objectivity' used in the proposition.

9 Reflectance dispositions are intrinsic to typical objects in typical conditions. An exception according to Alex Byrne (personal correspondence) can be found with photosensitive chemicals.
} 
Primitivism most broadly understood is the view that the colors are sui-generis properties (Yablo 1995; Westphal 2005). ${ }^{10}$ However, the view often also builds in at least Objectivism and Realism (Byrne and Hilbert 2007; Allen 2011). There is no reason why there cannot be a primitivism that also builds in Incompatibility. Further, there is no special reason why there cannot be (typically) extrinsic primitive properties. Thus, primitivism can be modified to accommodate Dependence and the three other propositions: Incompatibility, Realism, and Objectivism. Some will think that primitivism is ontologically excessive. Anyone who thinks this and who holds Dependence has reason to prefer an extrinsic micro-structuralism. ${ }^{11}$ Some will be convinced that micro-structuralist views should be rejected, because they cannot accommodate our core beliefs about color. In particular, there is an issue with micro-structuralism accommodating Johnston's Revelation: that the essential nature of the colors is fully revealed in standard visual experience (Johnston 1992). Anyone who has such worries and who holds Dependence has reason to prefer extrinsic primitivism. Which of these two views is ultimately correct is outside the scope of this article.

Although micro-structuralism is compatible with Dependence (in the logical sense relevant above), it may happen that there are actually no extrinsic micro-structural properties which are plausibly the colors. Prior to an in-depth investigation into the physical extrinsic properties causally relevant to color vision we cannot know for sure. It looks like this investigation has not been carried out in-depth, for it has been assumed that colors are intrinsic (Whittle 2003; Foster 2011). Certainly, there has been no attempt in philosophy to discover whether any micro-structural causes of color experiences depend on the colors of objects in the surround. It cannot be assumed that an investigation would fail to yield micro-structural properties that are extrinsic in the right way: the micro-structural world is very complicated with many causes of color experiences (Nassau 1983, 1997). If there is no single micro-structural property extrinsic in the right way which is plausibly, for instance, the property blue, perhaps the strategy of resorting to disjunctions of micro-structural properties would succeed. Ultimately, whether there are extrinsic micro-structural properties or disjunctions of them which are plausibly the colors is an empirical question that cannot be answered here. If no such properties are actually available, primitivism looks to be the extant Dependence-compatible alternative. Many notable figures think primitivism is the correct view on what the colors are, and so an extrinsic primitivism cannot be discounted prior to further investigation (Allen 2011; Campbell 1993, 2005; Gert 2008; Westphal 2005; Yablo 1995). ${ }^{12}$

\footnotetext{
10 See Allen (2011) for a further discussion on how to understand the idea that colors are sui generis properties.

11 Primitivism is compatible with the colors being physical properties in the broad sense defined by supervenience physicalism (Jackson 1993; Chalmers 1996) but not narrowly physical. So, primitivism does not require property dualism. It does, though, require additional properties over those talked about in the sciences.

12 Of course, there is room for entirely novel views to be developed which are compatible with Dependence and the three propositions. For instance, what about a view to the effect that colors are complex disjunctions of spatial relational properties which depend on relations between reflectances? For example, the property
} 
It is important not to confuse Dependence with the claim that the apparent colors, as developed by Noë (2004, pp. 143-144), change dependent on the surround. Noë seems to think that the apparent colors are mind-independent properties of external objects. As one cannot do everything, I have assumed and will continue to assume that the colors (pointing to the green of grass, the blue of the sky, the yellow of the sun, etc.) are the only properties represented in experiences as of things having colors, so no apparent colors are. This seems like an intuitive assumption to make. Perhaps Noë's view is a way to secure something like Veridicality (that is, veridicality for the apparent colors) while holding onto Incompatibility and rejecting Dependence, but it comes at the price of rejecting the intuitive assumption mentioned by postulating mysterious apparent colors. The apparent colors cannot be green, blue, yellow, etc. (as referred to above), because these are the colors. So, what are they supposed to be? Ultimately, it may well be that an answer can be given, but there is no space to further address Noë's view in this article. I am providing a response to the color contrast argument that need not postulate anything like Noë's apparent colors. ${ }^{13}$

I now want to quickly turn to the epistemic version of the color contrast argument. This version of the argument interprets $\mathrm{P} 1^{\mathrm{con}}$ to be as follows:

$\mathrm{E} 1^{\text {con }}$. There is no reason to believe that one variant is veridical rather than another in intrapersonal color variation cases involving simultaneous color contrast effects and typical observers in typical conditions (or something similar).

In reply to the epistemic version of the argument, I propose one accept E1 ${ }^{\text {con }}$ but reject that the best explanation of this is that Incompatibility, or Realism, or Incompatibility and Objectivism is false. Given the suggested, novel reply to the metaphysical version of the color contrast argument, what explains E1 $1^{\text {con }}$ is not that Incompatibility, or Realism, or Incompatibility and Objectivism is false, but that Dependence is true. Thus, provided this response to the metaphysical version of the color contrast argument succeeds, the epistemic version of the argument can be quickly dismissed using Dependence.

\section{Responses to objections}

I realize that the mentioned novel response to the color contrast argument using Dependence is not going to be popular. Reflectance dispositionalists like Byrne and Hilbert (2003a) and Tye (2000) will not like it because, as I said, it is incompatible with their view on color. Relationalists (Cohen 2004, 2009), selectionists (Kalderon 2007; Mizrahi 2007), and relativists (Brogaard 2010; Egan 2010) will not like it, because it partly undermines the motivation for their views by undermining the color contrast argument. So, in this last section, I anticipate and respond to seven objections against it. This section shows that the suggested, novel response is a live option, as the objections against it can be met.

\section{Footnote 12 continued}

red $=$ the property of $R_{1}$ being to the right of $R_{2}$, to the left of $R_{5} \ldots$ or $R_{3}$ being to the left of $R_{6}$, in front of... or... Prima facie, this view is compatible with Dependence, Incompatibility, Realism, and Objectivism.

13 For a critical discussion of Noë see Allen (2009a). 
The first objection is that intuitively, the colors are independent of the surround. In reply, I concur but only to a degree. To explain what I mean, I must differentiate between two propositions. The first, 'Weak-Independence,' is that the determinable colors are mostly independent of the surround, and the second, 'Strong-Independence,' is that the determinable and determinate colors are always independent of the surround. As I said, dissimilar to what is the case with determinate colors, contrast effects seldom cause an object to appear a different determinable color. Thus, what I meant by 'I concur but only to a degree' was that I agree that intuitively, the colors are independent of the surround but only to the degree required by Weak-Independence. I seriously doubt that it is intuitive that the colors are independent of the surround to the extreme degree required by Strong-Independence. Causally, shapes are not even always independent of surround (black holes warp the shapes of things).

One may insist it is Strong-Independence that is intuitive not Weak-Independence. I disagree, but even if this insistence is right, I think we have good reason to reject Strong-Independence. Assuming one already accepts the intuitive stance that the color of a whole can depend on the colors of its parts (Sect. 2), saying that the color of an object can depend on the colors of objects that are merely in its surround in addition to objects that are parts of it seems a small sacrifice to avoid the color contrast argument and not reject Incompatibility or Veridicality. So, I think we have good reason to reject Strong-Independence. Further, I think there is good reason to be suspicious of any intuitions in its favor. As color contrast effects rarely cause an object to appear a different determinable color, one may underestimate their prevalence. This is why Hardin (1988) sought to emphasize the pervasiveness and importance of color contrast. Thus, it would hardly be surprising for our intuitions to favor Strong-Independence even though it is Weak-Independence that is really true.

The second objection is that color contrast effects would remain even if they were causally isolated from the surround within which they are placed, so it seems the colors of objects do not causally depend on the surround. The reason people believe this is that if one were to look at, for example, the central squares (see Fig. 1) through a reduction scope (a tube that blocks light reflected by surrounding objects), the color contrast effects would no longer be visible. This is a poor reason to believe the relevant assertion. Plausibly, using a reduction scope would result in falsidical perceptions of color contrast effects, for these scopes restrict the background information that would normally be available to one's visual system. ${ }^{14}$ The analogy is with size where we know that restricting the background information that would normally come into one's eyes can result in illusions. The Ames room (a distorted room that uses perspective to fool the perceptual system about the sizes of things) is an example of this (Gibson 1979 , p. 281; Runeson 1988, p. 296). In fact, most will already admit that reduction scopes result in falsidical perceptions of related colors, which are colors that can only be seen as a result of contrast, like white, gray, black, and brown. If reduction scopes result in falsidical perceptions, such scopes cannot be used to rule out the possibility that the colors of the central squares are causally dependent on the colors of the objects in their surrounds and mutatis mutandis for all simultaneous color contrast effects.

14 The same response is available for pink-tinted sunglasses. These restrict the background information that would normally be available. So, we can say they result in falsidical perceptions. 
The third objection is that there are cases for which Dependence seems ill-equipped to provide the ecumenical response for which it was intended. The worrying cases are ones in which the color an object appears changes depending on a change in the viewing angle or in the viewing distance, where there is no infringement on the information that would normally be available. As there is no infringement, these cases cannot be set aside as abnormal ones in which at least one perception is falsidical like reduction scope cases can. Further, one cannot say that the object is both colors all over at once without denying Incompatibility, and one cannot say that it changes colors dependent on viewing angle or viewing distance without denying Objectivism. In response, physical objects are highly complex, as can be seen when looking through a high-power microscope, and so cannot be seen in their entirety from any one viewing angle or viewing distance. So, I believe that the friend of Dependence can preserve an ecumenical view by holding the plausible thesis that when viewing an object from different angles or distances one is always seeing different parts of the object. Given this thesis, one can say that an object really does have both the colors it appears to when viewed from one angle or distance and then another; but it is never the case that it has both colors all over at once, and it is never the case that its colors change mind-dependently.

One may retort that the different parts seen will often have substantial overlap. No overlapping part can be more than one color all over at once (a corollary of Incompatibility), so the object cannot really have both the colors it appears to when viewed from one angle or distance and then another. An intuitive reply is to insist on a dependence between the color of a whole and its parts. ${ }^{15}$ So, though a surface A (viewed from one angle or distance) and a surface B (viewed from another) can have an overlapping part that is, for instance, red, A and B can be different colors (all over). If $\mathrm{A}$ and $\mathrm{B}$ can be different colors, the object can really have both the colors it appears to from the different angles or distances. This kind of whole-part dependence is common with shapes. Further, anyone who wants to secure Veridicality has independent reason to hold that the color of a whole can depend on the colors of its parts. We know that the color a macro object appears is seldom the color its micro constituents appear. So, some kind of whole-part color dependence seems required to secure Veridicality and Incompatibility. I said that endorsing a whole-part color dependence is the intuitive reply to the color composition argument. More could be said about whole-part color dependence. It is enough that I have shown that there is a strategy to handle this objection.

The fourth objection concerns a case where the object being viewed rotates while the viewer rotates around it keeping angle and distance the same. This could result in a difference in color appearance as the object's colored surfaces change their spatial relations to surrounding objects. These cases are of no concern to the friend of Dependence. She need only say that rotating the object changes the surround of its surfaces thus resulting in its surfaces really changing their colors. This response on behalf of the proponent of Dependence poses no problem for Incompatibility, Realism, and

15 If this reply is correct, we have yet another condition on any properties which are plausibly the colors that micro-structural and primitivist views would need to meet. There is no logical problem with either kind of view being modified to accommodate this further condition. 
Objectivism. All it requires is that one understands 'the surround' as involving spatial relations such as 'under,' 'above,' 'left of,' 'right of,' etc. So, the cases in question are quite easily dealt with. Whether this is the intuitive sense of 'surround' is irrelevant. A technical notion can be used.

The fifth objection is that ordinary practice for determining an object's real color in contrast cases is to remove it from its surround (Tye 2000, p. 155). In retort, I admit that some examples suggest that ordinary practice is to treat color contrast effects as if they result in illusions. For example, I confess that if one bought yellow paint for a highlight wall in a room in which the other walls were green, one would not return the paint claiming that 'the wall changed the paint's color.' However, there are other examples in which it would seem that people do not treat color contrast effects as if they result in illusions. For instance, most would probably describe the colors of an artwork (e.g. a Piet Mondrian) as if they are really there and not an illusion caused by color contrast. In fact, in my experience people often talk about using color contrast to make a color more vibrant, brighter, or darker, not just to make it appear in those ways. For example, at the Van Gogh museum in Amsterdam the labels say he used contrast to make his work vibrant, not that he used contrast to merely make his work appear that way. So, I think that ordinary practice is at best inconsistent. As such, it does not provide strong evidence either for or against Dependence.

The sixth objection is a concern to the effect that there are motivations analogous to those for accepting Dependence for accepting a dependence on lighting conditions. Now, I am very willing to accept that the determinate and determinable colors are not always independent of lighting if that is what it takes to secure Incompatibility, Realism, and Objectivism. Notice that the proponent of these propositions can accept a dependence on lighting. This said, one could also argue against pervasiveness for lighting. In color contrast cases the colors of objects really appear to change (see Figs. 1, 2). However, one could argue that in typical lighting conditions the colors do not appear to change. One could make a phenomenological distinction between the colors objects appear and whether their colors appear obstructed by light or shadow or concealed (to some degree) because of darkness. According to this view, on a sunny day, for example, one needs to differentiate whether the sun makes the object appear a different color or whether it makes it appear coated in yellow sunlight. The view holds that once these kinds of distinctions are made, one can defend the idea that the colors of objects do not appear to change dependent on lighting in typical conditions. ${ }^{16}$ To be clear, I am not advocating for this view, only its possibility.

Finally, the seventh objection is that the motivation for the novel response using Dependence to the color contrast argument is question begging, for minimally it relies on Incompatibility and Veridicality, and Veridicality implies Realism. ${ }^{17}$ This objection confuses the dialectic. I suggested that the color contrast argument is flawed at $\mathrm{M} 2^{\text {con }}$, because what explains $\mathrm{M} 1^{\mathrm{con}}$ is that Dependence is true. So, to defend the color contrast

\footnotetext{
16 A view on color constancy similar to the one I am espousing here, which I take to be an intuitive position, can be found in Brown (2014). He develops the view much more thoroughly than I can in this article.

17 The minimal motivation runs as follows: Assuming Pervasiveness, one must reject either Incompatibility or Veridicalty, or accept Dependence. So, if one accepts Incompatibility and Veridicality, one must accept Dependence.
} 
argument, my opponent must argue that those who accept Incompatibility, Realism, and Objectivism cannot justifiably explain $\mathrm{M}^{\text {con }}$ using Dependence. One does not have to assume that Realism and Incompatibility are false when defending them from their opponents. So, I am free to use these propositions to motivate Dependence. Hence, for my opponent to reject Dependence and so reject the novel explanation of $\mathrm{M} 1^{\text {con }}$ he must undercut my motivation for Dependence without just assuming the falsity of Incompatibility or Realism (or both).

My opponent may try to do this is by providing an independent argument for the falsity of Incompatibility or Realism (or both). Any attempt to provide an independent argument for the falsity of Incompatibility or Realism (or both) is beside the point given the scope of this article. Also, importantly, arguing against Realism is not open to selectionists, relationalists, and relativists who must hold that the proposition is true. These views (standardly) provide an ecumenical answer to color variation cases under which everyone is right. ${ }^{18}$ Finally, whatever one may think of Incompatibility and Realism, the dialectical force of what I have said should not be underestimated. For one, it must be admitted that the novel, ecumenical reply has advantages over the dogmatic response and so is worth considering.

Acknowledgements I would like to thank Philip Percival and Penelope Mackie for help with a much early version of this paper. I would also like to thank Kelly Ann Schmidtke, Jon Robson, James Andow, and Ben Smart for helpful comments and advice. I am also appreciative of two anonymous referees who helped to improve this paper even further.

Open Access This article is distributed under the terms of the Creative Commons Attribution 4.0 International License (http://creativecommons.org/licenses/by/4.0/), which permits unrestricted use, distribution, and reproduction in any medium, provided you give appropriate credit to the original author(s) and the source, provide a link to the Creative Commons license, and indicate if changes were made.

\section{References}

Allen, K. (2009a). Being coloured and looking coloured. Canadian Journal of Philosophy, 39, 647-670. Allen, K. (2009b). Inter-species variation in colour perception. Philosophical Studies, 142, 197-220.

Allen, K. (2010). Locating the unique hues. Rivista di Estetica, 43, 13-28.

Allen, K. (2011). Revelation and the nature of colour. Dialectica, 65, 153-176.

Boghossian, P. A., \& Velleman, J. D. (1989). Colour as a secondary quality. Mind, 98, 81-103.

Brogaard, B. (2010). Perspectival truth and color primitivism. In C. Wright \& N. Pederson (Eds.), New waves in truth and pluralism. Basingstoke: Palgrave Macmillan.

Brown, D. (2014). Colour layering and colour constancy. Philosophers' Imprint, 14, 1-31.

Byrne, A. (2006). Comments on Cohen, Mizrahi, Maund, and Levine. Dialectica, 60, 223-244.

Byrne, A., \& Hilbert, D. R. (2003a). Color realism and color science. Behavioral and Brain Sciences, 26, $3-21$.

Byrne, A., \& Hilbert, D. R. (2003b). Color realism redux. Behavioral and Brain Sciences, 26, 791-794.

Byrne, A., \& Hilbert, D. (2004). Hardin, Tye and color physicalism. Journal of Philosophy, 101, 37-43.

Byrne, A., \& Hilbert, D. (2007). Color primitivism. Erkenntnis, 66, 73-105.

Campbell, J. (1993). A simple view of colour. In J. Haldane \& C. Wright (Eds.), Reality, representation and projection. Oxford: Oxford University Press.

Campbell, J. (2005). Transparency versus revelation in color perception. Philosophical Topics, 33, 105-115. Chalmers, D. J. (1996). The conscious mind. New York: Oxford University Press.

18 An eliminativist may worry that evolution poses a threat to Veridicality (Chalmers 2006). I refer my reader to Byrne and Hilbert (2007) who have a thorough reply. 
Chalmers, D. J. (2006). Perception and the fall of Eden. In T. Gendler \& J. Hawthorne (Eds.), Perceptual Experience. Oxford: Oxford University Press.

Cohen, J. (2004). Color properties and color ascriptions: A relationalist manifesto. Philosophical Review, $113,451-506$.

Cohen, J. (2006a). Colour and perceptual variation revisited: Unkown facts, alien modalities, and perfect psychosemantics. Dialectica, 60, 307-319.

Cohen, J. (2006b). Color, variation, and the appeal to essences: Impasse and resolution. Philosophical Studies, 133, 425-438.

Cohen, J. (2009). The red and the real. Oxford: Oxford University Press.

Egan, A. (2010). Comments on Jonathan Cohen's the red and the real. Analytic Philosophy, 53, 306-312.

Fine, K. (1994). Essence and modality. Philosophical Perspectives, 8, 1-16.

Foster, D. (2011). Color constancy. Vision Research, 51, 674-700.

Gert, J. (2008). What colors could not be: An argument for color primitivism. The Journal of Philosophy, $105,128-155$.

Gibson, J. J. (1979). The ecological approach to visual perception. Boston: Houghton Mifflin.

Goethe, J. (1810). Theory of colours (C. L. Eastlake, Trans.). Cambridge, MA: MIT Press, 1970. (Original English publication, 1840).

Hardin, C. L. (1988). Color for philosophers. Indianapolis: Hackett.

Hardin, C. L. (2004). A green thought in a green shade. Harvard Review of Philosophy, 12, 29-39.

Hilbert, D. (1987). Color and color perception: A study in anthropocentric realism. Stanford: CSLI.

Hume, D. (2004). A treatise of human nature. Retrieved from http://www.earlymoderntexts.com/authors/ hume. (Original work published 1739).

Jackson, F. (1993). Armchair metaphysics. In J. Hawthorne \& M. Michael (Eds.), Philosophy in mind. Amsterdam: Kluwer.

Jackson, F., \& Pargetter, R. (1987). An objectivist guide to objectivism about colour. Revue Internationale do Philosophie, 41, 127-147.

Johnston, M. (1992). How to speak of the colours. Philosophical Studies, 68, 221-263.

Kalderon, M. E. (2007). Color pluralism. The Philosophical Review, 116, 563-601.

Kripke, S. (1972). Naming and necessity. Cambridge: Harvard University Press.

Liao, S. (2012). What are centered worlds. Philosophical Quarterly, 62, 294-316.

Lewis, D. (1979). Attitudes De Dicto and De Se. Philosophical Review, 88, 513-543.

Locke, J. (2004). An essay concerning human understanding. Retrieved from http://www.earlymoderntexts. com/authors/locke. (Original work published 1698).

Maund, B. (1995). Colours: Their nature and representation. New York: Cambridge University Press.

McKitrick, J. (2003). A case for extrinsic dispositions. Australasian Journal of Philosophy, 81, 155-174.

Mizrahi, V. (2007). Color objectivism and pluralism. Dialectica, 60, 283-306.

Nassau, K. (1983). The physics and chemistry of color. The fifteen causes of color. New York: Wiley.

Nassau, K. (1997). The causes of color. In Alex Byrne \& David Hilbert (Eds.), The philosophy of color (Vol. 1)., Readings on Color Cambridge, MA: MIT Press.

Noë, A. (2004). Action in perception. Cambridge, MA: MIT Press.

Roberts, P. (2014). Parsing the rainbow. Synthese, 191, 1793-1811.

Roberts, P., \& Schmidtke, K. (2012). In defense of incompatibility, objectivism, and veridicality about color. Review of Philosophy and Psychology, 3, 547-558.

Runeson, S. (1988). The distorted room illusion, equivalent configurations, and the specificity of static optic arrays. Journal of Experimental Psychology: Human Perception and Performance, 14, 295-304.

Thompson, E. (1995). Colour vision: A study in cognitive science and philosophy of perception. New York: Routledge.

Tye, M. (2000). Consciousness, color, and content. Cambridge, MA: MIT Press.

Watkins, M. (2002). Rediscovering colors: A study in pollyana realism. Dordrecht: Kluwer.

Westphal, J. (1987). Colour: A philosophical introduction. Oxford: Basil Blackwell.

Westphal, J. (2005). Conflicting appearances, necessity and the irreducibility of propositions about colours. Proceedings of the Aristotelian Society, 105, 219-235.

Whittle, P. (2003). Contrast colours. In R. Mausfeld \& D. Heyer (Eds.), Colour perception: Mind and the physical world. Oxford: Oxford University Press.

Yablo, S. (1995). Singling out properties. Philosophical Perspectives, 9, 477-502. 